\title{
The Epidemic of Substandard and Falsified Medications in Iraq: Evaluating the Effectiveness of National Pharmacovigilance Alerts to Community Pharmacies
}

\author{
Ali Azeez Al-Jumaili, ${ }^{1}$ - Manal Mohammed Younus ${ }^{3,4} \cdot$ Mena Ziad Saleh $^{1,5}$
}

Accepted: 28 February 2021 / Published online: 16 April 2021

(c) The Author(s), under exclusive licence to Springer Nature Switzerland AG 2021

\begin{abstract}
Background Assessing Iraqi experience with the impact of substandard and falsified (S/F) medicines can help other countries deal comprehensively with the underlying causes of this multifactorial problem. The tools used in this study to assess strategies to prevent the use of S/F medications can be used in other developing countries. This study investigated the problem of S/F medications at three levels: the Ministry of Health (MOH), pharmaceutical company representatives, and community pharmacists.

Objectives Study objectives were to evaluate the effectiveness of alerts about S/F medications issued by the national Iraqi Pharmacovigilance Center (IqPhvc) to community pharmacies and to explore the reasons and potential solutions for this problem from the perspective of both pharmaceutical companies and pharmacists.

Methods This was an exploratory mixed-method study. The qualitative phase comprised seven 1-h semi-structured interviews and one focus group conducted via Zoom. Thematic analysis was used to analyse the qualitative data. The findings of the qualitative phase were then used to develop the survey items. The quantitative phase included an electronic survey distributed among pharmacists via two professional Facebook groups between 23 April and 19 May 2020. The Kruskal-Wallis test was used to measure differences in pharmacists' knowledge of and ability to detect S/F medications according to their years of experience in the private sector.

Results Over the last 5 years (2016-2020), the IqPhvc received 183 reports about S/F medications from representatives of 25 international companies. Only 29 (15.8\%) of the reports were about falsified medications; the majority were about substandard (parallel) medicines. We interviewed 12 pharmacists (11 male, 1 female) representing ten large international pharmaceutical companies. We also received surveys from 590 pharmacists, of whom 475 (80.9\%) were women. Although $72 \%$ of the participants had not received any training in the identification of S/F medications, $59.4 \%$ of them easily identified S/F medications. Likewise, approximately three-quarters of the participating pharmacists recognized genuine registered medications through three means: medication price sticker, cost, and packaging features. Although $61 \%$ of the pharmacists followed-up alerts about S/F medications, only $25.6 \%$ were willing to report S/F medications.

Conclusions Most reports to the IqPhvc were about substandard medications. Participants of the two study phases agreed on several reasons for the problem of S/F medications, including their low prices, the unavailability of registered medications, the lengthy medicine registration process, and inadequate awareness of S/F medications among healthcare providers and the public. They also agreed that national alerts and price stickers are helpful in the identification of S/F medications. Community pharmacists can increase their efforts to report S/F medicines, but they need training, awareness, and tools. The study highlighted the need for a track-and-trace system to detect S/F medicines in the supply chain. In brief, the problem of $\mathrm{S} / \mathrm{F}$ medication is multifaceted. Reducing it will require effective collaboration among different entities, including health officials, border agencies, healthcare providers, and registered pharmaceutical companies.
\end{abstract}

Extended author information available on the last page of the article 


\section{Key Points}

National alerts about substandard and falsified (S/F) medications and price stickers are helpful in the identification of S/F medications.

$\mathrm{S} / \mathrm{F}$ medications are prevalent in the private sector for several reasons, including the low prices and greater profitability of S/F medications, the unavailability of registered medications, the lengthy medicine registration process, and inadequate awareness of $\mathrm{S} / \mathrm{F}$ medications among healthcare providers and the public.

A track-and-trace system is necessary for the detection of $\mathrm{S} / \mathrm{F}$ medicines in the supply chain.

The problem of $\mathrm{S} / \mathrm{F}$ medication in the private sector is multifaceted. Solving this problem will require effective collaboration between different entities, including health officials, border agencies, healthcare providers, and registered pharmaceutical companies.

The tools used in this study to assess the strategies implemented to prevent the use of $\mathrm{S} / \mathrm{F}$ medications can be used in other developing countries.

\section{Introduction}

In 2015, the Organisation for Economic Co-operation and Development estimated the value of the global counterfeit pharmaceutical industry to be about US $\$ 200$ billion annually [1]. All regions of the world are affected by the problem of substandard/falsified (S/F) medicines but to different extents. The problem is more pronounced in low- to middleincome countries, where it is estimated that $10 \%$ of medical products are $S / F$ [2]. A recent survey of 200 physicians in Sweden found that one-third of their patients may have taken $\mathrm{S} / \mathrm{F}$ medicines [3]. According to a recent report from the Iraqi Ministry of Health (MOH), 60-70\% of medications in the private sector are $\mathrm{S} / \mathrm{F}[4,5]$. This problem poses a real threat to patient medication safety, decreases trust in medicines, jeopardizes the trust between patients and healthcare providers (HCPs), and has socioeconomic consequences [2].

The World Health Organization (WHO) defines substandard medicines as "authorized medical products that fail to meet either their quality standards or specifications, or both" [2]. Substandard medicines usually enter a country through unofficial avenues and may be exposed to substandard storage and shipping conditions $[2,6]$. In other words, illegal diversion (parallel importing) occurs when a medicine is produced for sale in one country but illegally enters and is sold in another. The regulators in the second country refuse to use these parallel medications because they can harm patients [7]. According to the WHO, falsified medicines "deliberately/fraudulently misrepresent their identity, composition or source" [2]. Falsified medications are manufactured under substandard conditions and then packaged to look like authentic medications. They either do not contain active ingredient(s) or contain more/less than the stated dose [8].

The pivotal goal of pharmacovigilance is to monitor the benefit-risk balance of any medical intervention and/or product, with a positive value indicating a favourable safety profile. On the other hand, unclear benefit would indicate an unsafe intervention. As such, the definition of pharmacovigilance can be expanded to include monitoring of S/F medical products since they shift the balance towards risk [9].

The Iraqi pharmaceutical sector mainly relies on imported medicines; the market share of domestic medicines was $<25 \%$ of the total pharmaceutical volume in 2020 [5]. Medicines in Iraq are regulated by the MOH. The Directorate of Technical Affairs is responsible for this mission and conducts four essential regulatory activities: registration, pharmacovigilance, good manufacturing practice certification, and quality and safety control [5]. The medicine, its manufacturing site, the marketing authorization holder, and the medicine price must be registered with the Registration Department to be officially available in Iraq in both public and private sectors [5]. The public sector is under governmental control, and medicines are securely made available to all health institutions across the country through the State Company for Marketing Drug and Medical Appliances (KIMADIA), the MOH body responsible for procurement and distribution of medical products [10]. The private sector is partly regulated by the $\mathrm{MOH}$ and partly by the Syndicate of Iraqi Pharmacists (SIP) [5]. The pathway of medicines availability in the private sector involves different players: The scientific bureau(s) that represent the marketing authorization holder(s) provides the wholesalers with the medicines, and they in turn provide the medicines to the community pharmacies [10].

Evaluations of national pharmacovigilance alerts about $\mathrm{S} / \mathrm{F}$ medications and pharmacists' abilities to detect and report S/F medications are relatively scarce. To the best of our knowledge, no previous Iraqi study has aimed to identify the causes of and practical solutions for this large-scale challenge, which began after 2003 when the importation of medicines to the private sector became decentralised.

Our study investigated the problem at three levels: the $\mathrm{MOH}$, pharmaceutical company representatives, and community pharmacists. Additionally, we used a unique comprehensive method (exploratory mixed method) to answer our study questions about the effectiveness of the Iraqi 
Pharmacovigilance Center (IqPhvc) alerts, price stickers, and other current strategies to minimize the distribution and use of $\mathrm{S} / \mathrm{F}$ medications in the private sector. This evaluation of the experience in Iraq can help other countries to deal comprehensively with the underlying issues and to engage the stakeholders who can influence this multifactorial problem. The study objectives were to evaluate the effectiveness of the IqPhvc alerts about S/F medications sent to community pharmacies and to explore the reasons and potential solutions for this problem from the perspective of pharmaceutical companies and pharmacists.

\section{Methods}

This study triangulated three sources of data: IqPhvc reports, interviews with and/or a focus group involving pharmaceutical company representatives, and a survey of pharmacists. The study employed an exploratory mixed method (qualitative phase followed by quantitative phase) because the authors required real-world information about the problem of S/F medicines and its causes before developing the survey items. The qualitative phase helped the researchers assess the effectiveness of pharmacovigilance alerts from the pharmaceutical companies' point of view, and the interviewee comments were very helpful in understanding the whole complicated picture of this multifactorial problem.

The study proposal was approved by the ethical committees at the University of Baghdad College of Pharmacy and Iraqi MoH. No incentive was offered to participants. The survey was voluntary and anonymous, and the researchers de-identified the interview and focus group participants.

\subsection{Qualitative Phase}

The qualitative phase was conducted first to help develop the survey items (exploratory mixed method). For example, the findings from the qualitative phase helped in the development of the survey items related to identifying potential reasons and suggested solutions for the problem of S/F medications. The interviewees were safety/regulatory agents from international pharmaceutical companies or scientific bureaus.

The interview was semi-structured with open-ended questions. The interview guide was made up of three sections and included 16 questions in total. The first section included participant characteristics (job title, experience years, profession), perceptions about the reasons for S/F, and participant/company experience with $\mathrm{S} / \mathrm{F}$ medications. This section also asked about how community pharmacists identified S/F medications and the negative impact of S/F medications on registered medicine companies and patients. The second section included questions about participant perceptions of the effectiveness of the $\mathrm{MOH}$, the IqPhvc, and the SIP in preventing S/F medications. Finally, section three included questions about what policy and decision makers can do to minimize the distribution and use of S/F medications.

Contact information for representatives of international pharmaceutical companies was obtained from the IqPhvc. Purposeful sampling was used to select participants from companies who had reported S/F medications to the IqPhvc within the last 4 years.

The researchers conducted interviews with a maximally diverse set of interviewees from stakeholders in areas of pharmaceutical regulations and S/F medications. Interviewees were invited via phone and provided verbal consent before the interviews were conducted and recorded. The seven interviews and the focus group were conducted via the Zoom meeting platform because of the coronavirus disease 2019 (COVID-19) pandemic. The interviews lasted for about $60 \mathrm{~min}$ each, whereas the focus group took $2 \mathrm{~h}$. The interviews continued until saturation of the information was reached. The interviews were conducted in English by one researcher (AA, an expert in Social and Administrative Pharmacy), and a second researcher (MZ, a graduate student) acted as notetaker. The interviews were recorded and the recordings transcribed.

\subsubsection{Thematic Analyses}

The qualitative data were generated from the seven semistructured interviews and one focus group. The interview records were transcribed and the transcriptions crosschecked by the research team. The names of the interviewees and their companies were deidentified to maintain participant confidentiality. During the qualitative analysis stage, the research team identified and developed themes from the participants' answers. The analysis followed the six phases of thematic analysis described by Braun and Clarke: familiarizing with data, generating initial codes, searching for themes, reviewing themes, defining and naming themes, and displaying the findings [11].

Inductive analytic methodology (data driven) was used, and a constructivist paradigm was followed for the qualitative phase. This means we did not rely on a previous framework to generate themes but constructed the themes from the common trends emerging from the participants' responses. The data item was each sentence of the participants' answers. Finally, to enhance the credibility and trustworthiness of the findings, peer-checking/debriefing was performed twice to validate the qualitative analysis.

\subsection{Quantitative Phase}

The quantitative phase included an English-language electronic survey (Qualtrics) distributed among pharmacists and 
the reports of $\mathrm{S} / \mathrm{F}$ medications submitted to the IqPhvc. The target participants were pharmacists from across the country with experience in the private sector. The survey was distributed via two professional Facebook groups (members of the SIP and Al-Multaqa Al-Sadalany) between 23 April and 19 May 2020. These are well-known national professional Facebook groups that include around 20,000 members (any pharmacist with a Facebook account). The survey was reposted every other day.

The authors used the findings of the qualitative phase in addition to some items from previous studies that were customized to fit the Iraqi private sector $[8,12]$. The authors also consulted current practising pharmacists before developing the survey to ensure the items were tailored to the domestic medicine market. Face validity of the new/modified survey items was checked by three experts in the field. Finally, a pilot study was conducted with ten community pharmacists to detect any unclear/inadequate questions, and the survey was revised accordingly.

The survey included five sections. Part 1 included six items about the responding pharmacist's characteristics. Part 2 included eight items related to the pharmacist's knowledge of and ability to detect S/F medications. Part 3 included seven items about the roles of the MOH, the IqPhvc, and the SIP in decreasing the distribution and use of S/F medications. Part 4 included eight items about the pharmacist's perceptions of $\mathrm{S} / \mathrm{F}$ medications (such as reasons and potential solutions for the problem of S/F medications). Part 5 included six items about the roles of current community pharmacists in decreasing the distribution and use of S/F medications. An additional question concerned the pharmacist's awareness of ten IqPhvc alerts about S/F medications in 2019 and 2020.

Pharmacists without experience in the private sector were excluded from the questions identifying some S/F medications that were subject to alerts from the IqPhvc. Additionally, only community pharmacists could answer questions addressing the roles of community pharmacists in decreasing the distribution and use of S/F medications (using display logic question).

\subsubsection{Statistical Analysis}

The Statistical Package for Social Sciences program (SPSS) version 24 (IBM SPSS Statistics, Armonk, NY, USA) was used for data analysis. Continuous characteristics were expressed as mean, range, and standard deviation. Categorical variables were expressed as frequencies and percentages. The answers to preparedness questions used the 5-score Likert scale: strongly disagree, disagree, neutral, agree, and strongly agree. The Kruskal-Wallis test was used to measure the differences in pharmacists' knowledge of and ability to detect $\mathrm{S} / \mathrm{F}$ medications according to years of experience in the private sector. $\mathrm{P}$-values $<0.05$ were considered statistically significant.

\section{Results}

\subsection{Qualitative Findings}

The qualitative phase included seven individual interviews and one focus group. The interviewees (P1-P7) represented nine large international pharmaceutical companies, and the five (P8.1-P8.5) focus group participants represented a tenth company. All interviewees were pharmacists (11 male; 1 female), with experience in pharmaceutical companies ranging from 2 to 13 years. They were employed as quality pharmacovigilance compliance agents, local safety representatives, sale managers, medical affairs managers, or distributor managers.

The qualitative findings are presented in five main sections: main reasons behind the availability of S/F medications, current strategies to minimize the distribution and use of S/F medications, the effectiveness of alerts from the IqPhvc in decreasing the distribution and use of S/F medications, the negative effects of $\mathrm{S} / \mathrm{F}$ medications, and recommendations from representatives of pharmaceutical companies to decrease the distribution and use of S/F medications. The cited tables include the main themes and subthemes of and participants' quotes from within these sections.

\subsubsection{Main Reasons Behind the Availability of Substandard/Falsified (S/F) Medications}

According to the representatives of pharmaceutical companies and a scientific bureau, there are five main reasons (themes) behind the prevalence of $\mathrm{S} / \mathrm{F}$ medications in the private sector: the current $\mathrm{MOH}$ regulations, unavailability of registered medications, lower prices of S/F medicines, inadequate awareness, and inadequate border control. Details and interviewees' quotes are shown Table 1.

\subsubsection{Current Strategies to Minimize the Distribution and Use of S/F Medications}

Four strategies to minimize the distribution and use of $\mathrm{S} / \mathrm{F}$ medications are currently in place: detecting S/F medications in the private market, developing and distributing S/F alerts to drug stores and community pharmacies, increasing ways to identify $\mathrm{S} / \mathrm{F}$ medications, and promoting awareness among HCPs (Table 2).

Representatives of pharmaceutical companies/scientific bureaus are the main detectors and reporters of S/F medications available in community pharmacies. They detect S/F medications and submit reports to the IqPhvc. When the 


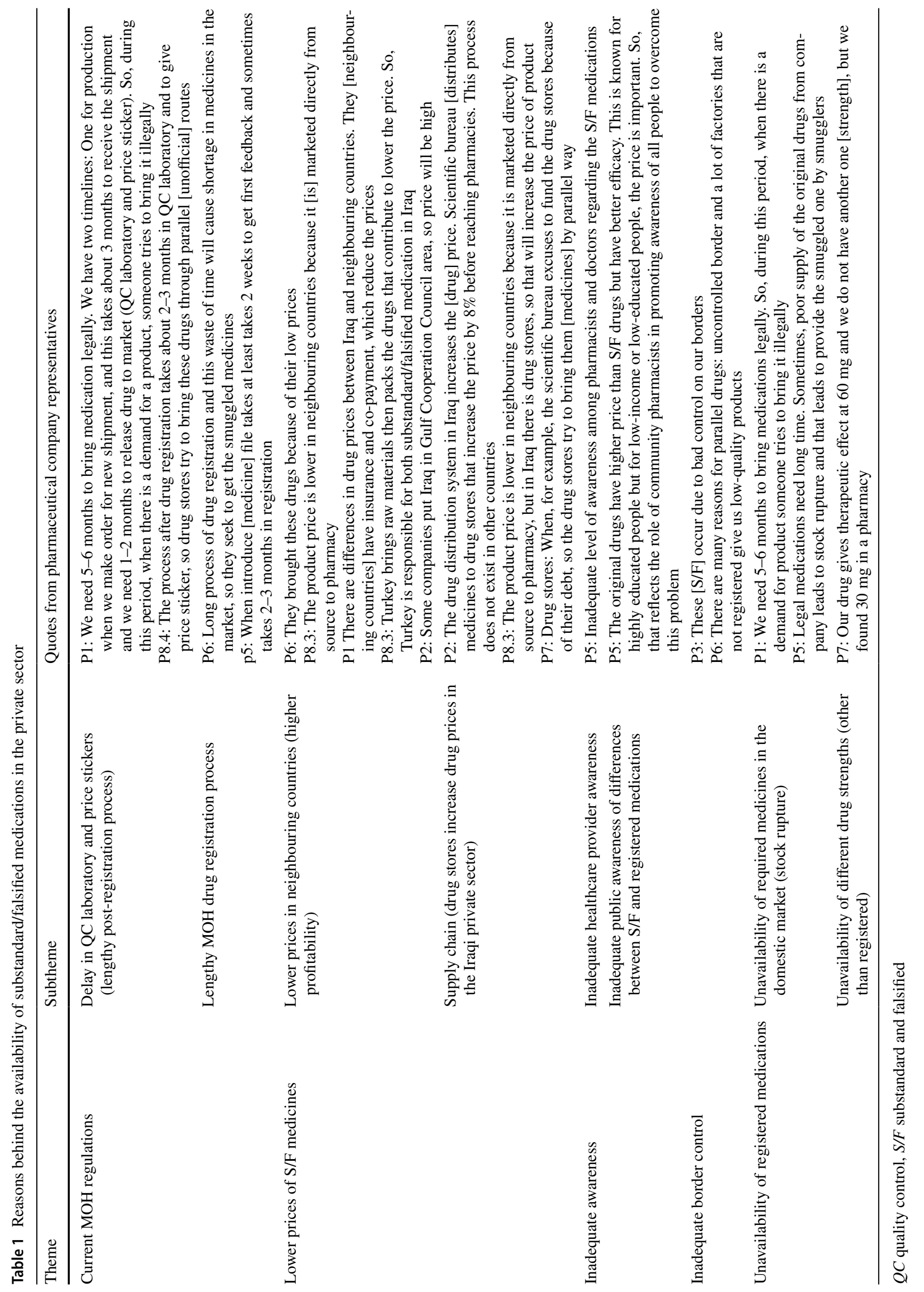




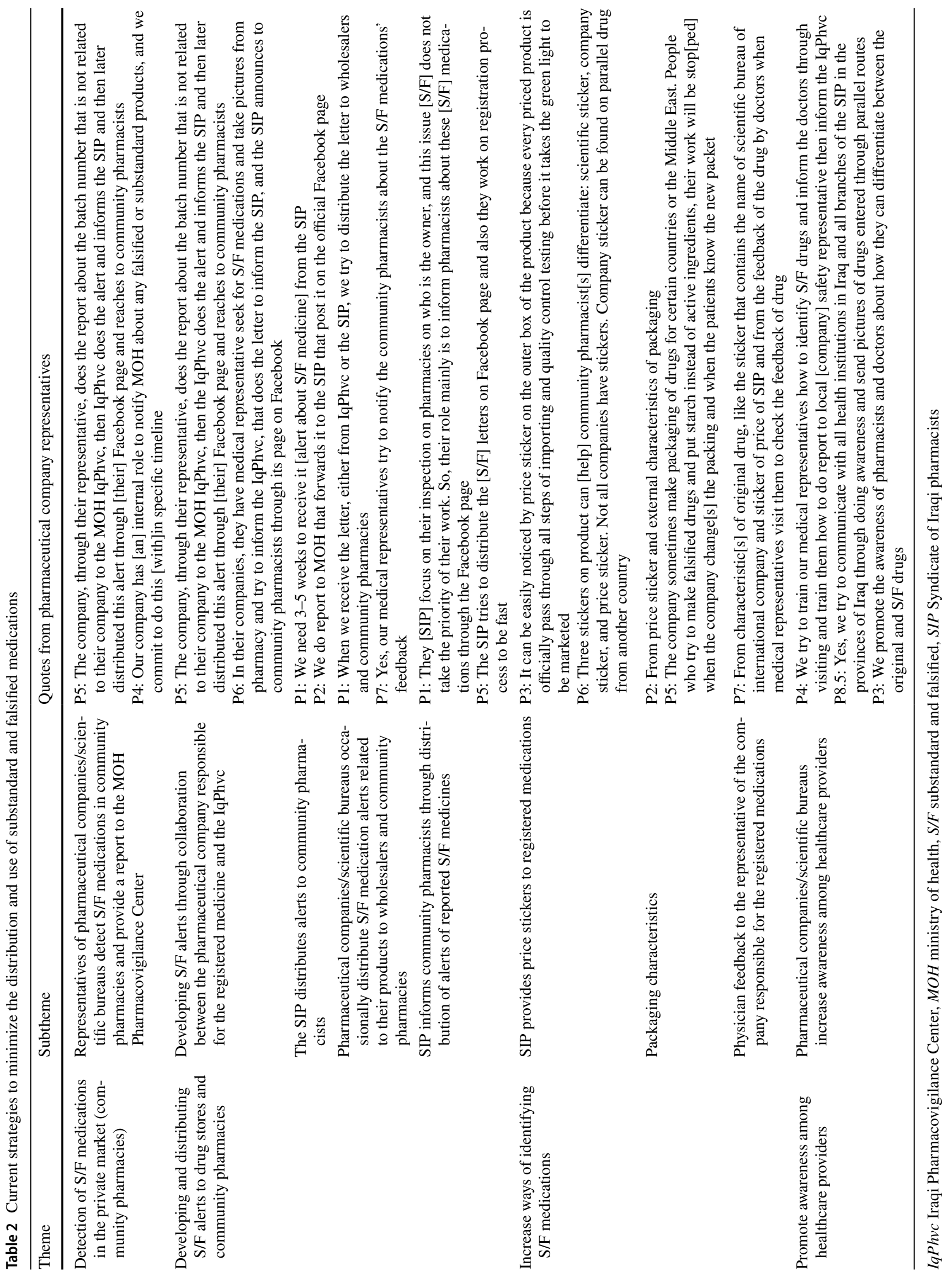


IqPhvc receives an $\mathrm{S} / \mathrm{F}$ report from a registered pharmaceutical company, an alert is developed and sent to the SIP to distribute to community pharmacists via their official and Facebook pages. In addition to the SIP, some pharmaceutical companies/scientific bureaus occasionally distribute $\mathrm{S} / \mathrm{F}$ medication alerts related to their products to wholesalers and community pharmacies.

Increasing the number of ways in which $\mathrm{S} / \mathrm{F}$ medications can be identified to help community pharmacists recognize them is essential. The main distinct sign is the SIP price sticker. These stickers are only provided for registered medications, so any imported medications without such a price sticker are probably S/F. Some companies change their packaging after a product has been falsified, which can also help distinguish between registered and falsified medications. The presence of a genuine company sticker can also help distinguish genuine from falsified medications but not parallel medications, which are genuine products that have entered the country through unofficial channels. Occasionally, physician feedback to the registered medication's company can also help identify S/F medications. Currently, it is primarily pharmaceutical companies/scientific bureaus that undertake to increase awareness among HCPs (physicians and pharmacists) working in the private sector, whereas the IqPhvc promotes awareness among pharmacists working in the public sector.

\subsubsection{Effectiveness of Alerts from the Iraqi Pharmacovigilance Center (IqPhvc) in Decreasing the Distribution and Use of $S / F$ Medications}

Almost all interviewees were satisfied with the role of the IqPhvc in providing alerts about and promoting awareness of $\mathrm{S} / \mathrm{F}$ medicines among hospital pharmacists. However, they requested more collaboration between the IqPhvc and other departments/entities since $\mathrm{S} / \mathrm{F}$ medication is a multifactorial problem (Table 5). Examples of interviewee comments about the role of the IqPhvc and the effectiveness of their alerts are included in Table 3.

Table 3 Evaluating the effectiveness of alerts from the Iraqi Pharmacovigilance Center in minimizing the distribution and use of substandard and falsified products in the private sector: views of registered companies

\begin{tabular}{|c|c|c|}
\hline Theme & Subtheme & Quotes from representatives of registered companies \\
\hline \multirow{6}{*}{$\begin{array}{l}\text { Effectiveness of IqPhvc } \\
\text { alerts to decrease the } \\
\text { problem of S/F products } \\
\text { in the private sector }\end{array}$} & $\begin{array}{l}\text { Satisfied with role of IqPhvs in } \\
\text { alerting about } \mathrm{S} / \mathrm{F} \text { medicines }\end{array}$ & $\begin{array}{l}\text { P1: We appreciate their [IqPhvc] efforts, and they try to communicate with } \\
\text { other entities to inform pharmacies about these }[\mathrm{S} / \mathrm{F}] \text { medications }\end{array}$ \\
\hline & $\begin{array}{l}\text { IqPhvs increases the level of } \\
\text { awareness of hospital pharma- }\end{array}$ & $\begin{array}{l}\text { P2: They [IqPhvc] do their best efforts in announcing the letters to SIP and } \\
\text { inspection department }\end{array}$ \\
\hline & cists about $\mathrm{S} / \mathrm{F}$ medicines & $\begin{array}{l}\text { P4: Despite limited resources of MOH IqPhvc and [the difficult] work environ- } \\
\text { ment inside [the] MOH, IqPhvc is currently doing a great job. Their social } \\
\text { media are followed by many community pharmacists and they started to } \\
\text { upgrade their [pharmacists] awareness about these [S/F] drugs }\end{array}$ \\
\hline & & $\begin{array}{l}\text { P5: We noticed that they [IqPhvc] developed their work by making workshops } \\
\text { in neighbouring countries and bind Iraq to the Uppsala [Monitoring Centre] } \\
\text { and [the] International Society of Pharmacovigilance, in the world. They } \\
\text { [IqPhvc] increase level of awareness in governmental centres when patients } \\
\text { that recumbent in hospital buy this drug from outside the hospital and if drug } \\
\text { is falsified, pharmacists in hospital do report to MOH IqPhvc to inform them }\end{array}$ \\
\hline & $\begin{array}{l}\text { More effort and collaboration is } \\
\text { needed }\end{array}$ & $\begin{array}{l}\text { P5: IqPhvc members do their best efforts but need more cooperation with other } \\
\text { departments of } \mathrm{MOH}\end{array}$ \\
\hline & & $\begin{array}{l}\text { P7: They [IqPhvc] do their efforts but need more work to control this problem } \\
\text { P6: They [IqPhvc] do their best efforts, but need to do more, not just report to } \\
\text { the SIP and to Inspection Directorate. There are a lot of drugs that come by } \\
\text { parallel ways. When Inspection Directorate searched in [community] pharma- } \\
\text { cies in Iraq, they found many parallel drugs }\end{array}$ \\
\hline \multirow[t]{3}{*}{$\begin{array}{l}\text { Usefulness of IqPhvc alerts } \\
\text { to companies/scientific } \\
\text { drug bureaus }\end{array}$} & IqPhvc alerts are helpful & $\begin{array}{l}\text { P3: They always stand with an official importer against unknown counter- } \\
\text { feit goods that enter our country from unknown sources, which may have } \\
\text { unknown consequences during their use on our patients }\end{array}$ \\
\hline & & $\begin{array}{l}\text { P4: Yes, sure it [IqPhvc] is very helpful and triggers many further actions that } \\
\text { done by local distributers of the companies. They give information to discon- } \\
\text { tinue some products then forwarded to our company }\end{array}$ \\
\hline & $\begin{array}{l}\text { IqPhvc needs to collaborate with } \\
\text { other departments }\end{array}$ & $\begin{array}{l}\text { P6: IqPhvc must cooperate with other entities to solve this problem } \\
\text { P8.3: Yes, the IqPhvc alerts are helpful but it [IqPhvc] alone cannot fight this } \\
\text { problem }\end{array}$ \\
\hline
\end{tabular}

$I q P h v c$ Iraqi Pharmacovigilance Center, $M O H$ Ministry of Health, $S / F$ substandard/falsified 


\subsubsection{Negative Effects of S/F Medications}

The negative consequences of $\mathrm{S} / \mathrm{F}$ medications include the impact on the reputations of the original medicines, the profitability of the registered company, patient safety, and drug effectiveness. Some representative interviewee quotes are included in Table 4.

\subsubsection{Recommendations from Representatives of Pharmaceutical Companies to Minimize the Distribution and Use of S/F Medications}

Interviewee recommendations about how to minimize the distribution and use of $\mathrm{S} / \mathrm{F}$ medications in the private sector include five main strategies: enhance public and HCP awareness of $\mathrm{S} / \mathrm{F}$ medicines, conduct more frequent inspections of drug stores and community pharmacies and punish those who deal with S/F medications, enhance $\mathrm{MOH}$ regulations, adopt a tracking system, improve collaboration between the $\mathrm{MOH}$ and other ministries. Details and interviewee quotes are shown Table 5.

\subsection{Quantitative Findings}

\subsubsection{Reports of $\mathrm{S} / \mathrm{F}$ Medications to the IqPhvc}

The IqPhvc received 183 reports about S/F medications from the representatives of 25 international companies ( 11 brands and 14 generics) over the last 5 years (2016-2020). Only $29(15.8 \%)$ of the reports were about falsified medications, whereas the majority were about substandard (parallel) medicines. Collaborative investigations between the IqPhvc and the registered pharmaceutical company that reported the $\mathrm{S} / \mathrm{F}$ medicine to the $\mathrm{MOH}$ identify whether the reported medicine is substandard or falsified. The highest number of reports (56) was in 2017, and the lowest (23) was in 2016; note that 2016 was the first year of receiving the reports. On the other hand, the number of reporting companies varied from five in 2016 to 11 in 2018. In 2017, only seven companies submitted $56 \mathrm{~S} / \mathrm{F}$ medication reports to the IqPhvc. The most commonly reported S/F medications belonged to three anatomical therapeutic chemical classes: Alimentary tract and metabolism (29.0\%), Cardiovascular system (21.0\%), and Nervous system (10.4\%) (Fig. 1).

Table 4 Negative effects of substandard and falsified medications on registered companies and patients' lives

\begin{tabular}{|c|c|c|}
\hline Theme & Subtheme & The quotes of Pharmaceutical company representatives \\
\hline \multirow[t]{4}{*}{$\begin{array}{l}\text { The negative impacts of } \\
\text { S/F medications }\end{array}$} & $\begin{array}{l}\text { Negative impact on reputation of } \\
\text { original medicines }\end{array}$ & $\begin{array}{l}\text { P2 They }[\mathrm{S} / \mathrm{F}] \text { affect company reputation, especially life-saving drugs, also } \\
\text { affect company profits } \\
\text { P3: S/F medicines did not contain the import licence, also these drugs affect } \\
\text { patient concern toward our company and affect reputation } \\
\text { P4: These drugs did not have the import licence, also these }[\mathrm{S} / \mathrm{F}] \text { drugs increase } \\
\text { patient concern toward our company and affect our reputation } \\
\text { P7: During our visit to a doctor to see feedback about our product, he told us } \\
\text { that our drug does not work and when we went to the pharmacy, we found that } \\
\text { drug was not from our company and had another dose [strength] }\end{array}$ \\
\hline & $\begin{array}{l}\text { Impact on profitability of registered } \\
\text { company }\end{array}$ & $\begin{array}{l}\text { P8.5 Yes, we found that sales of S/F form of our drug approximately } \$ 2 \text { million/ } \\
\text { year against the original one. They }[\mathrm{S} / \mathrm{F}] \text { affect the company reputation and } \\
\text { profitability } \\
\text { P7: Also, they }[\mathrm{S} / \mathrm{F}] \text { affect the sales and take the place of original drug in the } \\
\text { market } \\
\text { P6: Income of company will be affected when patient take the }[\mathrm{S} / \mathrm{F}] \text { drugs and } \\
\text { do not act well like life-saving drugs, which must be given to patient }\end{array}$ \\
\hline & $\begin{array}{l}\text { Negative impact on drug effective- } \\
\text { ness and patient safety }\end{array}$ & $\begin{array}{l}\text { P6: Patient took a product and he told the company that their drug did not work } \\
\text { well. When the company searched about the matter, it appeared this drug was } \\
\text { not related to them and a patient was admitted to coronary care unit } \\
\text { P1: Substandard drugs like insulin may be transported at bad conditions (high } \\
\text { temperature), and that affects the safety of these drugs }\end{array}$ \\
\hline & $\begin{array}{l}\text { Impact of inappropriate storage con- } \\
\text { ditions on substandard medicines }\end{array}$ & $\begin{array}{l}\text { P2: We found important antidiabetes drug and another one for pregnancy are } \\
\text { S/F } \\
\text { P6: The company has cold chain drugs, and one time they found a counterfeit } \\
\text { medicine from this cold chain product } \\
\text { P1: The problem in the substandard drug is only storage condition because they } \\
\text { are genuine like insulin or other peptides (cold chain) }\end{array}$ \\
\hline
\end{tabular}

$S / F$ substandard and falsified 

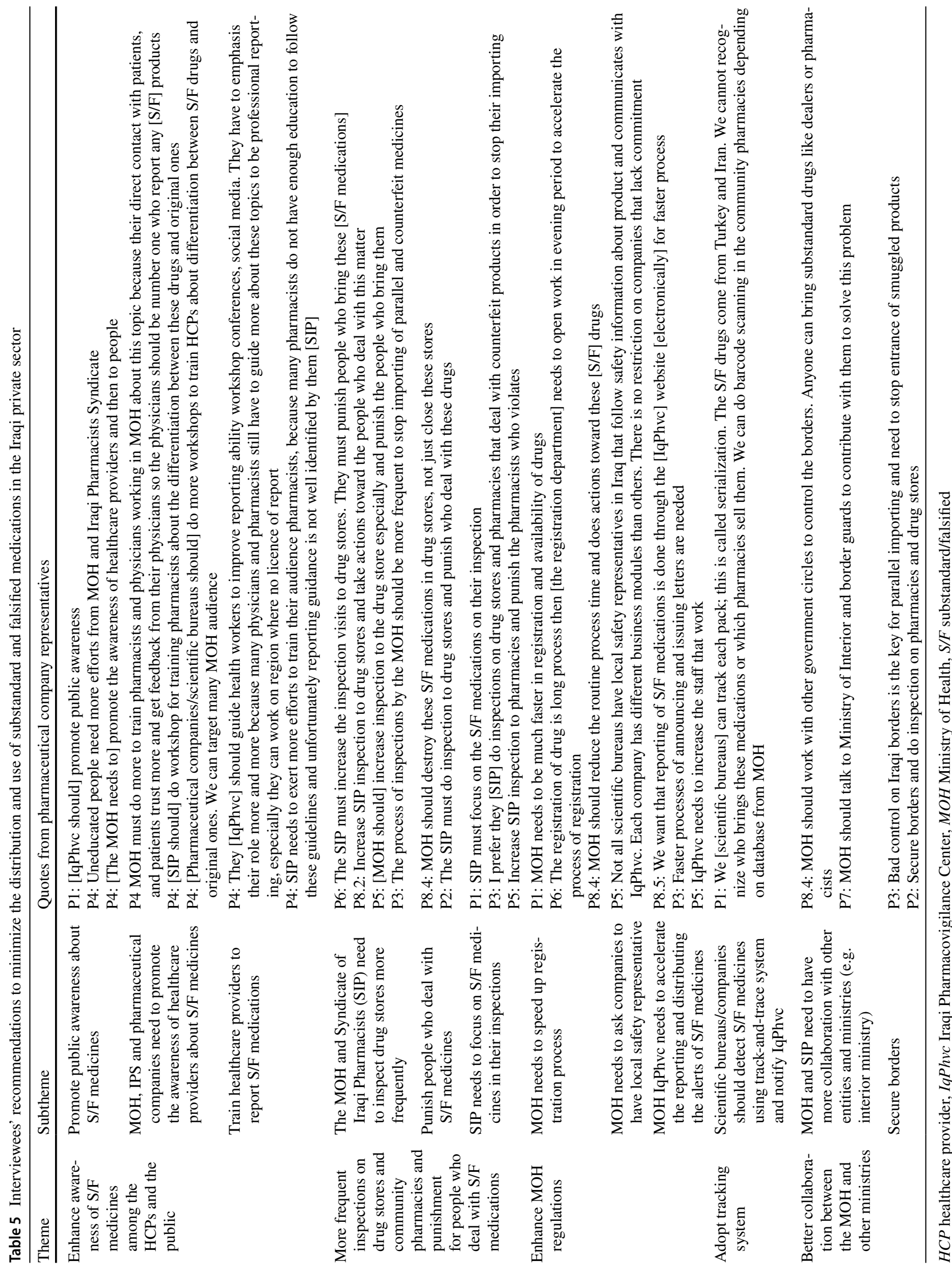


\subsubsection{Pharmacist Characteristics}

The authors received valid surveys from 590 pharmacists, $475(80.9 \%)$ of whom were women (Table 7). The mean \pm standard deviation age of participants was $32.6 \pm 7.6$ years (range 21-67). Almost all (96.4\%) had experience in the private sector. The average experience of the participants was $8.5 \pm 6.8$ years. The 19 participants who did not have experience in the private sector were excluded from the statistical analyses. Approximately half of the participants $(49.5 \%)$ worked at community pharmacies. The majority $(40 \%)$ of the participants were employees, and $34 \%$ were private business owners (Table 6).

\subsubsection{Pharmacist Knowledge of and Ability to Detect and Report S/F Medications}

Although more than two-thirds (72\%) of participants had not received any training in identifying $\mathrm{S} / \mathrm{F}$ medications, $59.4 \%$ did easily identify S/F medications. In total, $61 \%$ of the pharmacists had followed-up the SIP alerts about S/F medications and $78 \%$ were aware of the IqPhvc, but only one-quarter $(25.6 \%)$ of them were willing to report $\mathrm{S} / \mathrm{F}$ medications to the IqPhvc (Table 7).

\subsubsection{Entities and Means Helping Pharmacists Identify S/F Medications}

Among the $28 \%$ of the pharmacists who had received training in identifying S/F medications, $60 \%$ had received the training from pharmaceutical companies (Table 8). The majority of participants $(48.5 \%)$ indicated they usually became aware of the IqPhvc alerts through the SIP website and/or Facebook page. On the other hand, 19\% of participating pharmacists were unaware of these alerts. Approximately three-quarters (73\%) could identify genuine registered medications through three means: medication price sticker, cost, and package features (Table 8).

\subsubsection{Pharmacist Perceptions of the Prevalence of, and Reasons and Suggested Solutions for, the Distribution and Use of S/F Medications}

Approximately half (48\%) of the participants indicated that they thought $\mathrm{S} / \mathrm{F}$ medications represented $\geq 40 \%$ of the available medications in the private sector. Most of the participants (61\%) thought that S/F medications were for brand medicines. According to the pharmacists, the most common reasons for the availability of $\mathrm{S} / \mathrm{F}$ medications were the low price of $\mathrm{S} / \mathrm{F}$ medications (75.2\%), the unavailability of registered medicines in the market (52.1\%), and — to a lesser extent—-the lengthy drug registration process $(41.7 \%)$ and attracting low-income

Table 6 Characteristics of survey participants (pharmacists)

\begin{tabular}{|c|c|c|}
\hline Characteristic & Subcategory & Totals \\
\hline \multirow[t]{3}{*}{ Sex } & Female & $475(80.9)$ \\
\hline & Male & $112(19.2)$ \\
\hline & Total & $587(100.0)$ \\
\hline \multirow[t]{8}{*}{ Current workplace in the private sector } & Community pharmacy & $292(49.5)$ \\
\hline & Currently not working in private sector & $39(6.6)$ \\
\hline & Drug scientific bureau & $102(17.3)$ \\
\hline & Drug store (wholesaler) & $18(3.1)$ \\
\hline & International pharmaceutical company & $112(19.0)$ \\
\hline & National pharmaceutical company & $16(2.7)$ \\
\hline & Other & $11(1.9)$ \\
\hline & Total & $590(100.0)$ \\
\hline \multirow{3}{*}{$\begin{array}{l}\text { Do you have experience in the private sector? (such as com- } \\
\text { munity pharmacy, drug store, scientific bureau) }\end{array}$} & No & $19(3.2)$ \\
\hline & Yes & $566(96.8)$ \\
\hline & Total & $585(100.0)$ \\
\hline \multirow[t]{4}{*}{ Current position } & Employee & $234(40)$ \\
\hline & Manager/supervisor & $156(26)$ \\
\hline & Owner & $190(34)$ \\
\hline & Total & $580(100.0)$ \\
\hline
\end{tabular}

Data are presented as $N(\%)$ 


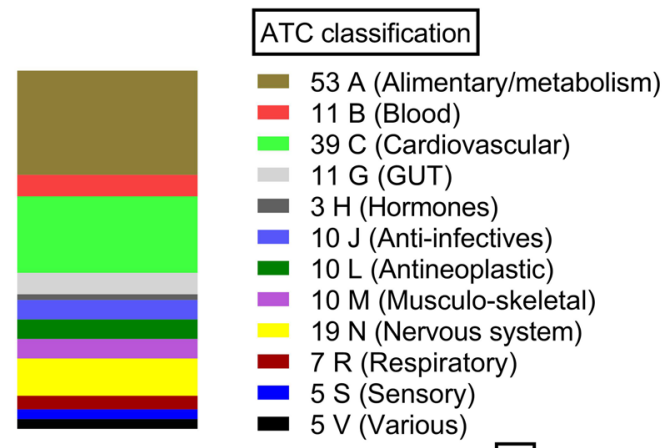

No. of S/F Reports (Total=183)

$\mathbf{a}$

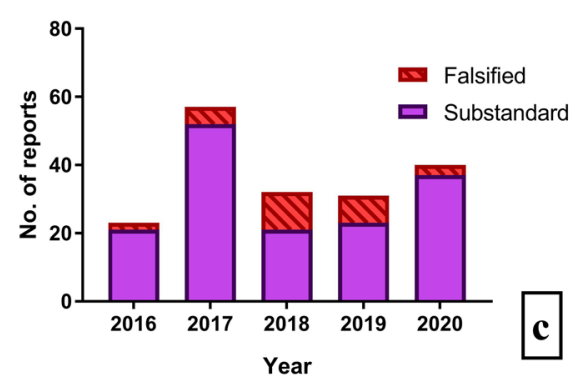

Fig. 1 The numbers of reported companies, the classes and the types of S/F medication reports to the IqPhvc over 5 years. a ATC classes of $\mathrm{S} / \mathrm{F}$ medications. b Number of S/F medicine reports and reported companies. $\mathbf{c}$ Number of S/F medicines over the 5 years. $\mathbf{d}$ Number of

patients (37\%). Almost two-thirds (66.9\%) of the pharmacists recommended a combination of four strategies to minimize the distribution and use of S/F medications: enhance border security, increase $\mathrm{MOH}$ inspections of the sources of S/F medications, and promote pharmacist and public awareness about S/F medications (Table 9).

\subsubsection{Pharmacist Ability to Identify Recently Posted S/F Medication Alerts}

When the participating pharmacists were asked to identify any of ten S/F medications reported by the IqPhvc in 2019-2020, only $16.7 \%$ could identify all ten medications. Additionally, more than half $(59.6 \%)$ identified five or fewer of the ten S/F medications, and only $40.4 \%$ identified more than five. Plavix tablets $(72.1 \%)$ and Depakin drops $(64.7 \%)$ were the most commonly identified S/F medications, and Agiolax powder $(40.1 \%)$ and Nebilet tablets $(37.2 \%)$ were the least common.

\subsubsection{Pharmacist Perceptions of the Impact of S/F Medications}

The pharmacists disagreed with the misconception that "parallel medications can solve the problem of a shortage in registered medications," with an average score of $2.8 \pm 1.4$
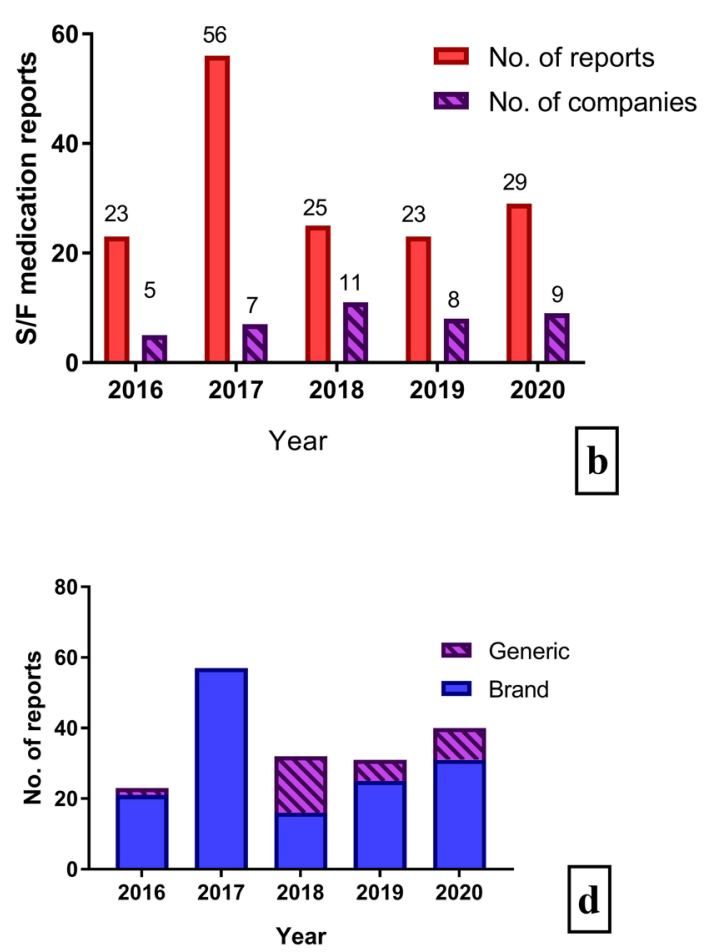

generic and brand $\mathrm{S} / \mathrm{F}$ medicines over the last 5 years. ATC anatomical therapeutic chemical, GUT genitourinary tract, IqPhvc Iraqi Pharmacovigilance Center, $S / F$ substandard/falsified

out of five. In contrast, the majority agreed (68.6\%) with the statement "parallel medications are negatively affected by improper storage/shipping conditions." On the other hand, three-quarters $(75 \%)$ of the participants believed that S/F medications could harm patients. Finally, the participants were divided about "parallel and falsified medications impose comparable risk to patient safety," with $41.5 \%$ agreeing and $35 \%$ disagreeing with the statement (Table 10).

\subsubsection{Pharmacist Perceptions of the Role of Health Officials in Decreasing the Distribution and Use of S/F Medications}

Most participants agreed that both IqPhvc alerts $(67.5 \%)$ and SIP price stickers $(88.9 \%)$ help pharmacists recognize $\mathrm{S} / \mathrm{F}$ medications. However, about half of the respondents $(49.9 \%)$ believed that the IqPhvc alerts were not helpful in terms of decreasing the presence of S/F medications in the private sector (Table 11). The majority of participants (62\%) believed that the current role of the $\mathrm{MOH}$ in drug registration was inadequate to prevent the presence of $\mathrm{S} / \mathrm{F}$ medications. Additionally, $63.8 \%$ believed that the current $\mathrm{MOH}$ inspection of drug stores is inadequate to minimize the presence of S/F medications. On the other hand, 81 and $87.6 \%$ of the participants believed that IqPhvc should 
Table 7 Pharmacist knowledge about and ability to detect and report substandard/falsified medications

\begin{tabular}{|c|c|c|c|c|c|}
\hline \multirow[t]{2}{*}{ Question } & \multicolumn{2}{|l|}{ Yes } & \multicolumn{2}{|l|}{ No } & \multirow[t]{2}{*}{$P$ value } \\
\hline & $n(\%)$ & Median & $n(\%)$ & Median & \\
\hline Can you easily identify S/F medications? & $350(59.4)$ & 7 & $240(40.6)$ & 7 & 0.855 \\
\hline $\begin{array}{l}\text { Do you regularly follow-up the warning alerts of S/F medi- } \\
\text { cations on the Facebook page of SIP? }\end{array}$ & $362(61)$ & 7 & $277(39)$ & 6 & 0.259 \\
\hline $\begin{array}{l}\text { Do you know how to report S/F medications to the } \mathrm{MOH} \\
\text { IqPhvc? }\end{array}$ & $148(33.5)$ & 9 & $391(66.5)$ & 6 & $0.000^{*}$ \\
\hline $\begin{array}{l}\text { Are you willing to report } \mathrm{S} / \mathrm{F} \text { medicines to the } \mathrm{MOH} \\
\text { IqPhvc? }\end{array}$ & $438(74.4)$ & 7 & $150(25.6)$ & 6 & 0.485 \\
\hline Are you aware of the IqPhvc and its duties? & $458(78)$ & 7 & $123(22)$ & 5 & $0.000^{*}$ \\
\hline $\begin{array}{l}\text { Have you received any kind of training to identify S/F } \\
\text { medications? }\end{array}$ & $162(28)$ & 7 & $423(72)$ & 6 & $0.031 *$ \\
\hline
\end{tabular}

Data are presented as $N(\%)$ unless otherwise indicated

IqPhvc Iraqi Pharmacovigilance Center, $M O H$ ministry of health, $S / F$ substandard and falsified, SIP Syndicate of Iraqi pharmacists

*Statistically significant at $<0.05$

promote awareness among the public and pharmacists about $\mathrm{S} / \mathrm{F}$ medications, respectively (Table 11).

\subsubsection{Current Community Pharmacy Roles Regarding S/F Medications}

Participation in this section was restricted to the pharmacists who worked in community pharmacies. The participating community pharmacists indicated that their pharmacies performed five of the roles regarding $\mathrm{S} / \mathrm{F}$ medications but neglected one essential practise: reporting suspicious medications to the IqPhvc (mean for answers $2.8 \pm 1.4$ ). The positive results included that the majority of community pharmacists educated co-workers and warned patients about $\mathrm{S} / \mathrm{F}$ medications, with average results of about $4.0 \pm 1.2$, indicating agreement. On the other hand, only $54 \%$ indicated their community pharmacies were following-up with the SIP alerts about S/F medicines (Table 12). Small percentages of the participants stated that their community pharmacies were not buying medications from reliable sources (17.2\%) or were examining every purchased medicine (14\%) (Table 12).

Table 8 The entities and means helping pharmacists to identify substandard/falsified medications

\begin{tabular}{|c|c|c|}
\hline Question & Subcategories & $N(\%)$ \\
\hline \multirow[t]{6}{*}{ From which entity did you receive training? } & Pharmaceutical company & $98(60)$ \\
\hline & Iraqi Pharmacovigilance center & $14(8.9)$ \\
\hline & Iraqi Pharmacist Syndicate & $7(4.5)$ \\
\hline & Personal effort & $32(19.8)$ \\
\hline & Others & $10(6.7)$ \\
\hline & Total & $161(100.0)$ \\
\hline \multirow{6}{*}{$\begin{array}{l}\text { You usually become aware of the Iraqi Pharmacovigilance } \\
\text { Center alerts about S/F medicines through: }\end{array}$} & I am unaware of these alerts & $113(19)$ \\
\hline & Iraqi Pharmacists Syndicate website/Facebook page & $283(48.5)$ \\
\hline & Pharmaceutical company representatives & $69(11.2)$ \\
\hline & Scientific drug bureaus & $78(13.9)$ \\
\hline & Other means, please specify & $39(6.7)$ \\
\hline & Total & $582(100.0)$ \\
\hline \multirow[t]{6}{*}{ You identify the registered genuine medications through: } & Price sticker & $77(13.8)$ \\
\hline & Cost & $16(2.8)$ \\
\hline & Package features & $44(7.7)$ \\
\hline & All the above & $419(73)$ \\
\hline & Other & $13(2.2)$ \\
\hline & Total & $569(100.0)$ \\
\hline
\end{tabular}


Table 9 Pharmacists' perceptions of availability of and reasons and suggested solutions for the substandard/falsified medication problem

\begin{tabular}{|c|c|c|}
\hline Question & Subcategory & $N(\%)$ \\
\hline \multirow{7}{*}{$\begin{array}{l}\text { What is the percentage of } S / F \text { medications available in the private } \\
\text { sector? }\end{array}$} & $0-10$ & $17(2.9)$ \\
\hline & $10-20$ & $55(9.3)$ \\
\hline & $20-30$ & $118(20.4)$ \\
\hline & $30-40$ & $114(19.4)$ \\
\hline & $40-50$ & $132(22.5)$ \\
\hline & $>5$ & $150(25.5)$ \\
\hline & Total & $586(100.0)$ \\
\hline \multirow{4}{*}{$\begin{array}{l}\text { Which medications are more likely to have S/F counterpart prod- } \\
\text { ucts? }\end{array}$} & Both brand and generic medicines & $207(35)$ \\
\hline & Brand medicines & $362(61.6)$ \\
\hline & Generic medicines & $18(3.4)$ \\
\hline & Total & $587(100.0)$ \\
\hline \multirow{7}{*}{$\begin{array}{l}\text { The most important reason behind the availability of S/F medica- } \\
\text { tions in the private sector }\end{array}$} & The lower price of $\mathrm{S} / \mathrm{F}$ medication & $436(75.2)$ \\
\hline & Unavailability of registered medicines in the market & $301(52.1)$ \\
\hline & Lengthy $\mathrm{MOH}$ drug registration process & $239(41.7)$ \\
\hline & $\begin{array}{l}\text { Pharmacies can attract more low-income patients who are } \\
\text { looking for cheaper medicines }\end{array}$ & $217(37.5)$ \\
\hline & Higher profitability of drug store (wholesaler) & $186(32.2)$ \\
\hline & $\begin{array}{l}\text { Inadequate public awareness about the risks of S/F medica- } \\
\text { tions }\end{array}$ & $184(31.9)$ \\
\hline & Pharmacist lack of awareness of the differences & $71(12.3)$ \\
\hline \multirow[t]{5}{*}{ Your suggestion to minimize $S / F$ medications include } & $\begin{array}{l}\text { Enhance border security control over smuggled products to } \\
\text { minimize entering S/F medications }\end{array}$ & $113(19.1)$ \\
\hline & Increase $\mathrm{MOH}$ inspections on the sources of $\mathrm{S} / \mathrm{F}$ medications & $48(8.1)$ \\
\hline & Promote pharmacist awareness about $\mathrm{S} / \mathrm{F}$ medications & $14(2.4)$ \\
\hline & Promote public awareness about $\mathrm{S} / \mathrm{F}$ medications & $11(1.9)$ \\
\hline & All the above & $396(66.9)$ \\
\hline \multirow{10}{*}{$\begin{array}{l}\text { Are you aware of the following Pharmacovigilance Center alerts } \\
\text { about S/F medications during 2019/2020? (yes) }\end{array}$} & Plavix $75 \mathrm{mg}$ tablet & $396(72.1)$ \\
\hline & Depakene drop & $356(64.7)$ \\
\hline & Betaserc $8 \mathrm{mg}$ tablet & $339(61.8)$ \\
\hline & Norgesic tablet & $277(50.4)$ \\
\hline & Diamicron tablet & $275(50.2)$ \\
\hline & Novonorm $2 \mathrm{mg}$ tablet & $270(49.2)$ \\
\hline & Coversyl $5 \mathrm{mg}$ tablet & $238(43.4)$ \\
\hline & Vastarel MR tablet & $238(43.4)$ \\
\hline & Agiolax granules & $220(40.1)$ \\
\hline & Nebilet $5 \mathrm{mg}$ tablet & $203(37.2)$ \\
\hline
\end{tabular}

\section{Discussion}

This study investigated the problem of S/F medications at three levels: health officials (IqPhvc), pharmaceutical company representatives, and community pharmacists. Additionally, we used a unique comprehensive method (exploratory mixed method) to answer the study questions about the effectiveness of the national pharmacovigilance alerts, the reasons behind the prevalence of $\mathrm{S} / \mathrm{F}$ medicines, and what else official entities can do to minimize the distribution and use of $\mathrm{S} / \mathrm{F}$ medications in the private sector.

\subsection{Ability of Pharmacists to Detect and Report S/F Medicines}

Although more than two-thirds of participants had not received training in the identification of $\mathrm{S} / \mathrm{F}$ medications, $59.4 \%$ could easily identify $\mathrm{S} / \mathrm{F}$ medications. In contrast, an Iranian study evaluating pharmacists' knowledge in detecting falsified drugs found only $13.6 \%$ had adequate knowledge of S/F medications [13]. The interviewees in our study confirmed that pharmaceutical companies were the main sources of training in the detection of S/F medications for HCPs in the private sector, whereas the IqPhvc provides 
Table 10 Pharmacist perceptions about the impact of substandard/falsified medications

\begin{tabular}{|c|c|c|c|c|c|c|}
\hline Questions & Strongly disagree & $\begin{array}{l}\text { Somewhat disa- } \\
\text { gree }\end{array}$ & $\begin{array}{l}\text { Neither agree nor } \\
\text { disagree }\end{array}$ & Agree & Strongly agree & Mean \\
\hline $\begin{array}{l}\text { Parallel medications can solve } \\
\text { the problem of a shortage in } \\
\text { registered medications }\end{array}$ & $189(32.5)$ & $56(9.6)$ & $107(18.4)$ & $172(29.6)$ & $58(10.0)$ & $2.8 \pm 1.4$ \\
\hline $\begin{array}{l}\text { Substandard (parallel) medica- } \\
\text { tions are negatively affected } \\
\text { by improper storage/shipping } \\
\text { conditions during the smug- } \\
\text { gling process }\end{array}$ & $68(11.6)$ & $44(7.5)$ & $71(12.2)$ & $117(20.0)$ & 284 (48.6) & $3.9 \pm 1.4$ \\
\hline $\begin{array}{l}\text { Substandard/falsified medica- } \\
\text { tions can harm patient health }\end{array}$ & $35(6.0)$ & $32(5.5)$ & $79(13.5)$ & $146(25.0)$ & $293(50.1)$ & $4.1 \pm 1.2$ \\
\hline $\begin{array}{l}\text { Substandard (parallel) and } \\
\text { falsified medications impose } \\
\text { comparable risk to patient } \\
\text { safety }\end{array}$ & $73(15)$ & $97(20)$ & $114(23.5)$ & $129(26.5)$ & $73(15)$ & $3.4 \pm 1.4$ \\
\hline
\end{tabular}

$N=581-585$. Data are presented as $N(\%)$ or mean \pm standard deviation unless otherwise indicated

training to pharmacists working in the public sector. The Iraqi $\mathrm{MOH}$ is a member of the WHO Global Surveillance and Monitoring System and regularly receives WHO global alerts about $\mathrm{S} / \mathrm{F}$ medicines and distributes them to public healthcare settings [5].

Approximately three-quarters of the participating pharmacists could recognize genuine registered medications through three means: medication price sticker, cost, and package features. Likewise, a recent Lebanese survey of pharmacists indicated that all participating pharmacists could identify the S/F medicines [14]. The interviews in our study also showed the benefit of the price stickers in the identification of registered medicines. The SIP medicine price stickers are unique and include the price and the SIP name and logo. They help pharmacists differentiate between registered imported medicines and S/F products. The absence of an electronic management system in community pharmacies makes it more difficult for pharmacists to detect $\mathrm{S} / \mathrm{F}$ medications. One interviewee mentioned that drug stores could send S/F medicines to pharmacies alongside registered medicines. For example, if a retail pharmacy orders ten packs of medicine $X$, a drug store may send five registered and five substandard packs without informing the pharmacy. However, the pharmacy can return any unwanted medicines (except cold chain ones) within 2 weeks. On the other hand, in developed countries, the main source of S/F medications is online purchasing. A previous study examined the efficacy of an adaptive learning algorithm called recursive trust labelling, which can help in the detection of fake medical websites selling S/F medications [15].

\subsection{Pharmacist Perceptions of the Reasons and Suggested Solutions for the Problem of S/F Medications}

According to three-quarters of the surveyed pharmacists and the majority of interviewees, the most common reason behind the availability of S/F medications was their low

Table 11 The perceptions of pharmacists about the role of MOH and IqPhvc in minimizing substandard/falsified medications

\begin{tabular}{|c|c|c|c|c|c|c|}
\hline Question & Strongly disagree & Somewhat disagree & $\begin{array}{l}\text { Neither agree } \\
\text { nor disagree }\end{array}$ & $\begin{array}{l}\text { Somewhat } \\
\text { agree }\end{array}$ & Strongly agree & Mean \\
\hline $\begin{array}{l}\text { The current } \mathrm{MOH} \text { regulations of the drug regis- } \\
\text { tration are adequate to prevent } \mathrm{S} / \mathrm{F} \text { medicines }\end{array}$ & $243(44.4)$ & $97(17.6)$ & $83(15.0)$ & $74(13.4)$ & $53(9.6)$ & $2.3 \pm 1.4$ \\
\hline $\begin{array}{l}\text { The current } \mathrm{MOH} \text { inspections to drug stores are } \\
\text { adequate to prevent } \mathrm{S} / \mathrm{F} \text { medicines }\end{array}$ & $246(44.6)$ & $106(19.2)$ & $96(17.4)$ & $70(12.7)$ & $33(6.0)$ & $2.2 \pm 1.3$ \\
\hline $\begin{array}{l}\text { The IqPhvc should promote public awareness } \\
\text { about } \mathrm{S} / \mathrm{F} \text { medications }\end{array}$ & $34(6.2)$ & $18(3.3)$ & $53(9.6)$ & $103(18.7)$ & $343(62.3)$ & $4.3 \pm 1.2$ \\
\hline $\begin{array}{l}\text { The IqPhvc should promote pharmacists' aware- } \\
\text { ness about S/F medications }\end{array}$ & $17(3.1)$ & $8(1.5)$ & $43(7.8)$ & $112(20.3)$ & $371(67.3)$ & $4.5 \pm 0.9$ \\
\hline
\end{tabular}

$N=551$. Data are presented as $N(\%)$ or mean \pm standard deviation unless otherwise indicated

$I q P h v c$ Iraqi Pharmacovigilance Center, $M O H$ Ministry of Health, $S / F$ substandard/falsified 
Table 12 The current community pharmacy roles concerning substandard/falsified medications

\begin{tabular}{|c|c|c|c|c|c|c|}
\hline Community pharmacy roles & Strongly disagree & Somewhat disagree & $\begin{array}{l}\text { Neither agree } \\
\text { nor disagree }\end{array}$ & Somewhat agree & Strongly agree & Mean \\
\hline $\begin{array}{l}\text { Our community pharmacy purchases } \\
\text { medications from known and reliable } \\
\text { sources }\end{array}$ & $14(5.8)$ & $30(11.4)$ & $49(18.5)$ & $65(24.9)$ & $103(39.4)$ & $3.8 \pm 1.2$ \\
\hline $\begin{array}{l}\text { In our community pharmacy, we examine } \\
\text { every purchased medicine }\end{array}$ & $9(3.4)$ & $24(10.6)$ & $46(17.7)$ & $77(29.7)$ & $100(38.6)$ & $3.9 \pm 1.1$ \\
\hline $\begin{array}{l}\text { Our community pharmacy follows-up with } \\
\text { the alerts of Iraqi Pharmacists Syndicate } \\
\text { about S/F medicines }\end{array}$ & $25(9.8)$ & $33(12.6)$ & $60(22.6)$ & $71(27.2)$ & $72(27.5)$ & $3.5 \pm 1.3$ \\
\hline $\begin{array}{l}\text { In our community pharmacy, we educate } \\
\text { co-workers about } S / F \text { medicines }\end{array}$ & $17(6.5)$ & $19(7.5)$ & $36(13.7)$ & $73(29.9)$ & $116(44.4)$ & $4.0 \pm 1.2$ \\
\hline $\begin{array}{l}\text { In our community pharmacy, we report } \\
\text { suspicious medicines to the IqPhvc }\end{array}$ & $62(23.3)$ & $37(14.8)$ & $85(32.7)$ & $34(13)$ & $42(16.1)$ & $2.8 \pm 1.4$ \\
\hline $\begin{array}{l}\text { In our community pharmacy, we warn } \\
\text { patients about the risks of } S / F \text { medicines }\end{array}$ & $16(6.4)$ & $12(4.5)$ & $38(14.5)$ & $73(27.9)$ & $122(46.7)$ & $4.1 \pm 1.2$ \\
\hline
\end{tabular}

$N=261$. Data are presented as $N(\%)$ or mean \pm standard deviation unless otherwise indicated

$I q P h v c$ Iraqi Pharmacovigilance Center, $S / F$ substandard/falsified

price. Low prices of substandard (parallel) medicines are probably due to lower prices in neighbouring countries and the multiple layers of the drug supply chain in the private sector. The survey also showed that some community pharmacies may find themselves under pressure from low-income customers to sell cheaper substandard (parallel) medicines. Similarly, a study of falsified antimalarial drugs in Cambodia found that "fake medicines were frequently preferred by patients and village health providers because of the lower price" [16]. However, the problem of poor-quality medicines may go beyond affordability and can be linked to the poor management of complex pharmaceutical supply chains and distribution networks [17].

Additionally, participants of the two study phases agreed that illegal filtration of medicines across borders can be due to non-restrictive border governance. Similarly, a recent Iraqi study about the national pharmaceutical industry showed deficiencies in border control strategies to prevent $\mathrm{S} / \mathrm{F}$ medicines from entering [18]. The other reported causes of S/F medicines included a shortage of registered medicines in the market $(52.1 \%)$ andto a lesser extent-the lengthy drug registration process $(41.7 \%)$. Since 2003 , the private sector has been experiencing chaotic changes and unsustainable supply, which encourages smugglers to bring in cheaper $\mathrm{S} / \mathrm{F}$ medicines [19].

\subsection{Role of Health Officials in Minimizing the Distribution and Use of S/F Medications}

Most participants (62\%) believed that the current role of the $\mathrm{MOH}$ in drug registration is inadequate to prevent the distribution and use of S/F medications. Similarly, the qualitative findings indicated that current $\mathrm{MOH}$ regulations were one of the five main reasons (themes) behind the availability of $\mathrm{S} / \mathrm{F}$ medications in the private sector.

Since 2003, KIMADIA (MOH) has been responsible for procuring and distributing medicines to public healthcare settings. Thus, there is a minimal chance of $\mathrm{S} / \mathrm{F}$ medicines entering this secure path [5]. On the other hand, in the private healthcare sector, the Inspection Directorate and the SIP are responsible for inspecting retail pharmacies, drug stores, and scientific drug bureaus [5]. However, a large number of private scientific drug bureaus $(>540)$ import medicines, and hundreds of drug stores $(>400)$ distribute medications $[10,20]$. The private sector is more vulnerable to the presence of S/F medicines for several reasons: multiple importers/distributers, uncontrolled borders, unstable medicine prices, and delays in the approval and registration of medicines.

In Africa, Nigeria's National Agency for Food and Drug Administration (NAFDAC) implemented a series of measures to prevent the distribution and use of S/F medications, which represented $68 \%$ of the total medications in the country in 2001 , and reduced that percentage by $80 \%$ within 3 years (2001-2004) [21]. Similarly, a Lebanese mixedmethods study in 2018 recommended imposing strict controls on medicines, enhancing law enforcement, promoting quality control testing, developing an S/F medicine reporting system, and providing continuing education to pharmacists [22]. However, some of the reported reasons for S/F medications entering the private sector may be beyond $\mathrm{MOH}$ control, including border inspections. Illicit trade across borders with neighbouring countries can further complicate the problem. 


\subsection{Negative Impacts of S/F Medications}

Findings from both the qualitative and the quantitative phases indicated that the negative impacts of S/F medications include endangering patient safety, undermining the effectiveness of the medicine, damaging the original medicine's reputation, and decreasing the profitability of the registered company. Falsified medicine formulations may contain insufficient active pharmaceutical ingredients, which can lead to a lack of clinical response and possibly death. For example, an interviewee stated that a patient was admitted to an intensive care unit after receiving a substandard anticoagulant post-heart catherization. A previous study reported incidences in which "vaccines" contained only water. For example, in a notorious case in Niger, over 50,000 people received a falsified meningitis vaccine during a meningitis epidemic in 1995, which resulted in the deaths of 2500 people and the permanent disability of many others [23]. Moreover, a recent Iraqi study showed that S/F medicines negatively affect the national pharmaceutical industry as national medicines cannot compete with their cheap prices [18].

\subsection{Strategies to Minimize the Distribution and Use of S/F Medications and Increase their Detection}

Our findings showed that the current strategies involve developing and distributing $\mathrm{S} / \mathrm{F}$ alerts to drug stores and community pharmacies, enhancing ways of identifying S/F medications using price stickers, and promoting awareness among HCPs. However, all these strategies appear to be ineffective at preventing the epidemic of S/F medicines in the private sector. The private sector does not have a track-andtrace system to record the source of S/F medicines and relies heavily on reporting by pharmaceutical company representatives. A Lebanese study measuring pharmacist awareness of and views about $\mathrm{S} / \mathrm{F}$ medicines reported that all participating pharmacists could define S/F medicines. The majority of participants identified the $\mathrm{S} / \mathrm{F}$ medicines by their effect $(67.7 \%)$, followed by cost (66.8\%). Additionally, the participants reported that they believed that pharmacists who dealt with S/F medicines did it for the "easy money" (87.9\%) and large profit $(86.5 \%)$. The study highlighted the need for additional campaigns to raise awareness of S/F medicines, with an emphasis on enhancing patient medication safety.

Iraq may learn from the EU's success in combating $\mathrm{S} / \mathrm{F}$ medicines. Since 2013, measures have consisted of four pillars. First, as of 9 February 2019, the EU requires two safety features: a unique identifier (a two-dimension barcode) and an anti-tampering device on the outer packaging. One or both of these features are available for medicines entering Iraq from Europe but they may not be available for all imported medicines. The second pillar involved securing the supply chain and good distribution practice at wholesaler and broker levels.
To date, no such measures exist in Iraq. Third, imported active substances and excipients are only allowed to enter Europe if they are accompanied by a written confirmation from the regulatory authority of the exporting country; this regulation is also implemented in Iraq. Finally, for internet sales, the websites of legal online pharmacies and approved retailers in the EU must carry a specific logo [24]. In contrast, there is no internet sale of medicines in Iraq, except for supplements.

The study had some limitations. It included a convenience sample for the survey and may not represent all provinces in the country. The 590 surveyed pharmacists may not represent the entire population of 20,000 pharmacists working in Iraq at the time of the study. However, we did our best to reach out to all professional Facebook groups for pharmacists in Iraq. The interview participants represented ten large brand companies, and small (generic) companies were not represented. From our pharmacy practice experience and interviewee responses, it is clear that most S/F medications target mainly brand medicines more than generic medicines because they are more expensive and more often requested.

The study highlighted the need for a track-and-trace system to be implemented to detect $\mathrm{S} / \mathrm{F}$ medicines in the supply chain. Health officials need to accelerate medicine registration and testing processes and collaborate with border security agencies to prevent $\mathrm{S} / \mathrm{F}$ medications from entering the country. Furthermore, health officials need to increase the frequency with which community pharmacies and drug stores are inspected, focusing on $\mathrm{S} / \mathrm{F}$ medications. Finally, more efforts are required to promote awareness among HCPs and the public about the risk of S/F medications and how to report them to health officials.

\section{Conclusions}

S/F medications have several negative clinical and economic impacts, including endangering patient safety, reducing drug effectiveness, ruining the reputation of original medicines, and reducing the profitability of registered companies. The vast majority of documented $\mathrm{S} / \mathrm{F}$ medicine reports concerned substandard (parallel) medications. Survey participants (community pharmacists) and the interviewees (pharmaceutical company representatives) both agreed on several reasons for the prevalence of S/F medications in the private sector, including the lower prices and higher profitability of S/F medications, the unavailability of registered medications, the lengthy medicine registration process, and the inadequate awareness among HCPs and the public. Interviewees also added insecure borders as one of the main causes of the prevalence of $\mathrm{S} / \mathrm{F}$ medications. The participants of the two phases also agreed that S/F medication alerts and price stickers are helpful for the identification of $\mathrm{S} / \mathrm{F}$ medications. Although the majority of the included pharmacists could identify S/F medications, a low percentage were willing to report them to health officials. 
The survey and interview questions from this study can be used in other developing countries to assess strategies implemented to prevent the distribution and use of S/F medications. Community pharmacists can increase their efforts to report S/F medicines, but they need training, awareness, and tools to do so. In brief, the problem of S/F medication in the private sector is multifaceted; decreasing it will require effective collaboration between entities, including health officials, border agencies, HCPs, and registered pharmaceutical companies.

Acknowledgments The authors thank all the pharmaceutical company representatives and pharmacists who agreed to participate in this study and shared their experience.

\section{Declarations}

Funding No funding was received for the conduct of this study.

Conflicts of interest Ali Azeez Al-Jumaili, Manal Mohammed Younus, and Mena Ziad Saleh have no conflicts of interest that are directly relevant to the content of this article.

Ethics approval The study proposal was approved by the ethical committees at the University of Baghdad College of Pharmacy and Iraqi Ministry of Health.

Consent to participate Verbal consent was obtained from interviewees before conducting and recording the interviews.

\section{Consent for publication Not Applicable.}

Availability of data and material Available from the authors on reasonable request.

\section{Code availability Not Applicable.}

Author Contributions Ali Azeez Al-Jumaili designed and executed the study, analysed the data, and wrote and reviewed the manuscript. Manal Mohammed Younus provided the S/F reports, recruited the interviewees, and participated in study design and reviewing the manuscript. Mena Ziad Saleh participated in data collection, analysing the qualitative data, and writing the manuscript.

\section{References}

1. Kristina ML, Acri NL. Pharmaceutical Counterfeiting: Endangering Public Health, Society and the Economy, C. FRASER Institute, Editor. 2018, fraserinstitute.org: https://www.fraserinst itute.org/sites/default/files/pharmaceutical-counterfeiting-endan gering-public-health-society-and-the-economy.pdf. Accessed 1 Oct 2020.

2. WHO, Substandard and falsified medical products. 2018, World Health Organization: https://www.who.int/en/news-room/ fact-sheets/detail/substandard-and-falsified-medical-products. Accessed 1 Oct 2020.

3. Funestrand H, Liu R, Lundin S, et al., Substandard and falsified medical products are a global public health threat. A pilot survey of awareness among physicians in Sweden. J Public Health (Oxford, England). 2019;41(1):e95-e102.

4. Alaa AlAlwan M. Health Situation in Iraq: Challenges and Priorities for Action, M. Iraqi Ministry of Health, Editor. 2019, Ministry of Health: Baghdad.

5. Al-Jumaili AA. Iraq Pharmaceutical Country Profile 2020, M.o. Health, Editor. 2020, World Health Organization: https://moh.gov. iq/upload/upfile/ar/1375.pdf.

6. Binagwaho A, Bate R, Gasana M, et al. Combatting substandard and falsified medicines: a view from Rwanda. PLoS Med. 2013;10(7):e1001476.

7. Attaran A, Barry D, Basheer S, et al. How to achieve international action on falsified and substandard medicines. BMJ. 2012;345:

8. Fadlallah R, El-Jardali F, Annan F, et al. Strategies and systemslevel interventions to combat or prevent drug counterfeiting: a systematic review of evidence beyond effectiveness. Pharm Med. 2016;30(5):263-76.

9. Preda, A. Pharmacovigilance in the new millennium: challenges, opportunities and new directions. J Pharmacovig. 2013;01.

10. Al-Jumaili AA, Hussain SA, Sorofman B. Pharmacy in Iraq: history, current status, and future directions. Am J Health Syst Pharm. 2013;70(4):368-72.

11. Creswell JW, Plano Clark VL. Designing and conducting mixed methods research. 2nd ed. CA: SAGE; 2011.

12. Hamilton WL, Doyle C, Halliwell-Ewen M, et al. Public health interventions to protect against falsified medicines: a systematic review of international, national and local policies. Health Policy Plan. 2016;31(10):1448-66.

13. Shahverdi S, Hajimiri M, Pourmalek F, et al. Iranian pharmacists' knowledge, attitude and practice regarding counterfeit drugs. IJPR. 2012;11(3):963-8.

14. Sholy L, Gard P, Williams S, et al. Pharmacist awareness and views towards counterfeit medicine in Lebanon. Int J Pharm Pract. 2018;26(3):273-80.

15. Abbasi A, Zahedi FM, Kaza S. Detecting fake medical web sites using recursive trust labeling. ACM Trans Inf Syst. 2012;30(4):22.

16. Rozendaal J. Fake antimalaria drugs in Cambodia. Lancet. 2001;357(9259):890.

17. Buowari O. Fake and counterfeit drug: a review. Afrimed J. 2012;3(2):1-4.

18. Ahmed KK, Al-Jumaili AA, Mutlak SH, et al. Determinants of national drug products acceptance across patients, pharmacists, and manufacturers: A mixed method study. J Gener Med. 2020. https://journals.sagepub.com/doi/abs/10.1177/1741134320 926625. p. 1741134320926625.

19. Ahmed Al-Humadi CL. Challenges of Iraq pharmaceutical market post-2003. Pharm Drug Regula Affair J. 2019'2(2). https://medwi npublishers.com/PDRAJ/PDRAJ16000116.pdf.

20. Pharmacist, S.o.I., Iraqi Pharmacists Syndicate Official Website. 2020, IPS: http://www.iraqipharm.com/.

21. Abiodun Raufu I. Nigeria leads fight against "killer" counterfeit drugs, in Bulletin of the World Health Organization. 2006, World Health Organization: https://www.who.int/bulletin/volumes/84/9/ 06-020906/en/. pp. 685-764.

22. Sholy L, Saliba C. Public awareness, experiences and views about counterfeit medicines in Lebanon. J Pharm Health Serv Res. 2018;9(2):161-9.

23. Kelesidis T, Kelesidis I, Rafailidis PI, et al. Counterfeit or substandard antimicrobial drugs: a review of the scientific evidence. J Antimicrob Chemother. 2007;60(2):214-36.

24. European Medicines Agency. Falsified medicines: overview, in Human regulatory. 2019, EMA: https://www.ema.europa.eu/en/ human-regulatory/overview/public-health-threats/falsified-medic ines-overview. Accessed 1 Oct 2020.w 


\section{Authors and Affiliations}

\section{Ali Azeez Al-Jumaili ${ }^{1,2}$ (D) Manal Mohammed Younus ${ }^{3,4}(\mathbb{D}) \cdot$ Mena Ziad Saleh $^{1,5}$}

$\triangle$ Ali Azeez Al-Jumaili

ali.baraak@copharm.uobaghdad.edu.iq

Manal Mohammed Younus manalyounus@gmail.com

Mena Ziad Saleh menaziad@gmail.com

1 University of Baghdad College of Pharmacy, Baghdad, Iraq

2 The University of Iowa College of Pharmacy, Iowa, USA
3 Pharmacovigilance Center, Iraqi Ministry of Health, Baghdad, Iraq

4 International Society of Pharmacovigilance (ISoP), London, UK

5 Directorate of Operations and Emergency Medical Services, Iraqi Ministry of Health, Baghdad, Iraq 